Research Article

\title{
Detection and Prediction of Internal-Caused Fire in Tunnel Cable by an Equivalent Transient Thermal Circuit Model
}

\author{
Yanwen Wang $\mathbb{D}^{1},{ }^{1}$ Xuran Zhang $\mathbb{D}^{1},{ }^{1}$ Le Wang $\mathbb{D},{ }^{2}$ and Yinsheng Wang $\mathbb{D}^{3}$ \\ ${ }^{1}$ School of Mechanical Electronic and Information Engineering, China University of Mining and Technology (Beijing), \\ Beijing 100083, China \\ ${ }^{2}$ North China Electric Power Test and Research Institute, \\ China Datang Corporation Science and Technology Research Institute Co., Ltd., Beijing 100040, China \\ ${ }^{3}$ Zhong Neng Power-Tech Development Co., Ltd., Beijing 100034, China
}

Correspondence should be addressed to Xuran Zhang; 810801559@qq.com

Received 7 October 2021; Accepted 30 October 2021; Published 11 November 2021

Academic Editor: Mingfeng Lei

Copyright $(2021$ Yanwen Wang et al. This is an open access article distributed under the Creative Commons Attribution License, which permits unrestricted use, distribution, and reproduction in any medium, provided the original work is properly cited.

Internal-caused cable fires are one of the most common cable fires, and anomalous temperature increase of the cable core is one of the first signs. However, when a cable is operating with electricity, the temperature of the core conductor cannot be monitored directly; therefore, this characteristic cannot be used in detection and prediction of internal-caused fire in electric cable effectively. An analogous transient thermal circuit model is created, simplified, and optimized to properly compute the temperature of the cable core. Afterward, by using the cable internal-caused fire experimental platform and adjusting current carrying capacity of the tested cable, an experiment is conducted for stimulating the very early stage of three-core cable internal-caused fire. The maximum relative errors of the transient thermal circuit model and the trisection transient thermal circuit model are less than $10 \%$ when comparing the experimental data with the calculation results, and the average relative error of the calculated value of trisection transient thermal circuit model is $1.08 \%$ after layered optimization. The algorithm model can satisfy the requirement for early detection and prediction in the very early stage of cable internal-caused fire.

\section{Introduction}

Cable tunnel engineering has advanced significantly in recent years, for example, $220 \mathrm{kV}$ Jiulong-Nanzhan cable tunnel project, $220 \mathrm{kV}$ Ninghai-Mochou cable tunnel project, and $220 \mathrm{kV}$ Qiuteng-Shanjiang cable tunnel project [1]. The electromagnetic environment in the cable tunnel is complicated, the air includes a considerable volume of flammable gas, and the humidity is high [2]. Power cables are usually laid crowded on cable tray in tunnel; thus, the probability of fire accidents would rise accordingly. Once a cable fire occurs, it becomes easy to spread and would cause serious losses [3-5]. In 2016, a fire broke out in the $66 \mathrm{kV}$ cable tunnel in Dalian, Liaoning Province. The accident caused a large area of power failure in Dalian for more than 6 hours. The road signal lights, waterworks, hospitals, banks, and supermarkets were influenced by power failure and could not operate normally, which seriously impacted the normal operation order of the city. In Holborn, London, UK, a cable fire broke out in a cable tunnel in 2015. It took firefighters seven hours to basically control the fire. The fire forced the evacuation of 5000 people in the city center, left over 3000 families and enterprises without power supply, and halted the urban operation [6]. Power line fires account for $36.8 \%$ of all fire incidents, and casualties account for 47.1 percent of total injuries, according to a statistical analysis of significant fires from 2008 to 2016 [7]. Thus, timely detection of cable fire especially before the fire and reduction of the probability of fire are of great significance to reduce casualties and economic losses [8-11]. Nevertheless, it is difficult to detect the fire as early as possible because cable tunnels are unattended and the fire detectors currently utilized cannot accurately detect the temperature of the cable in operation. When a fire is found, the fire has generally turned to the stage of intense combustion, and extinguishing the fire will become very difficult [6]. Figure 1 shows photos of three-core 


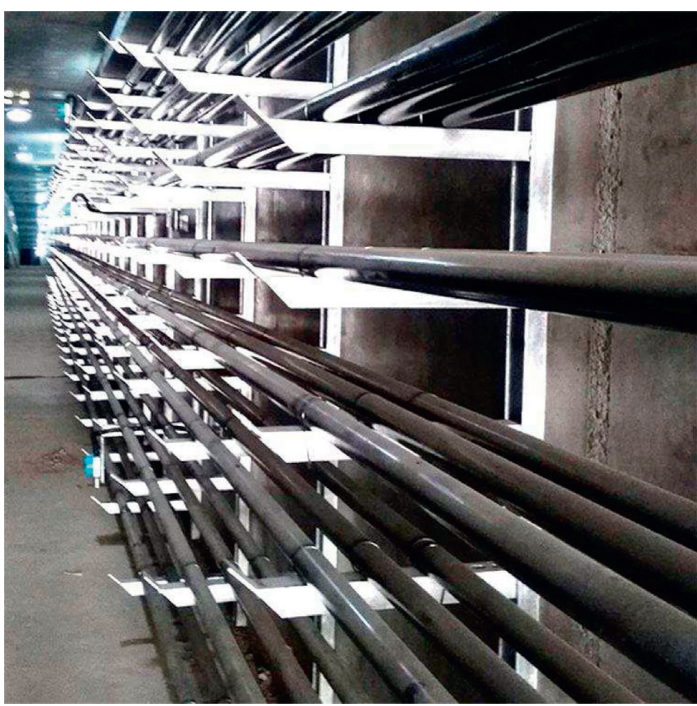

(a)

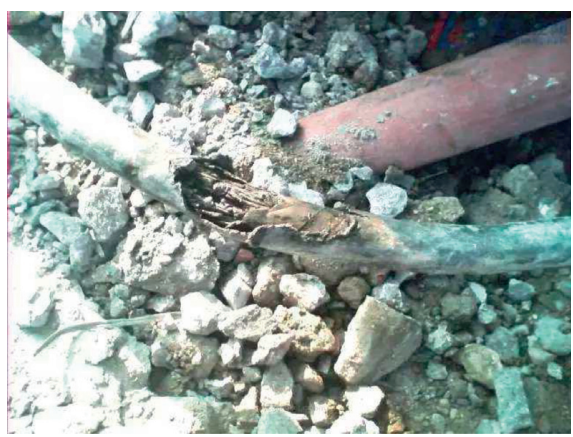

(c)

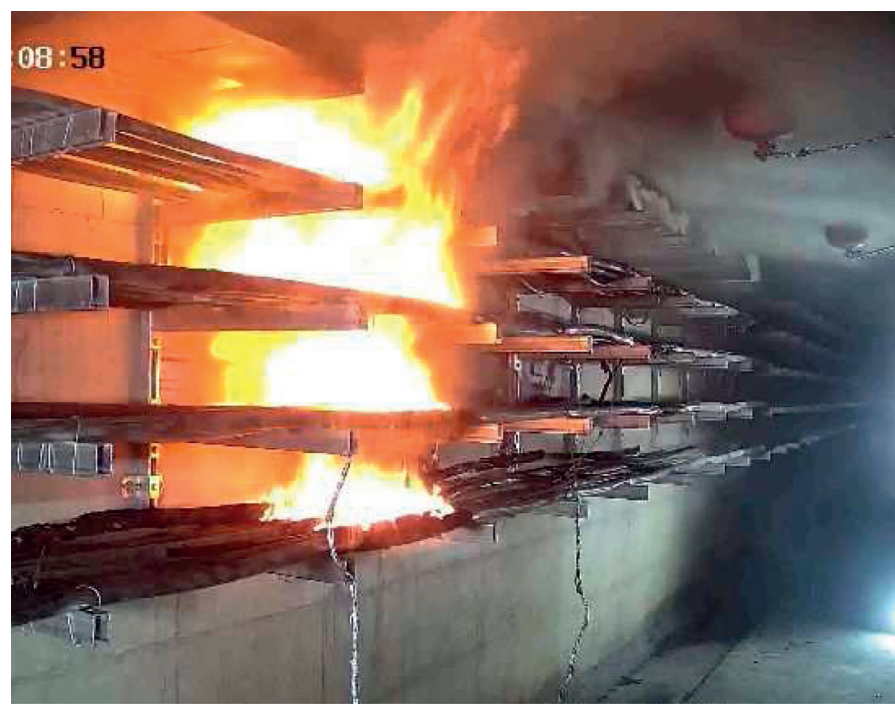

(b)

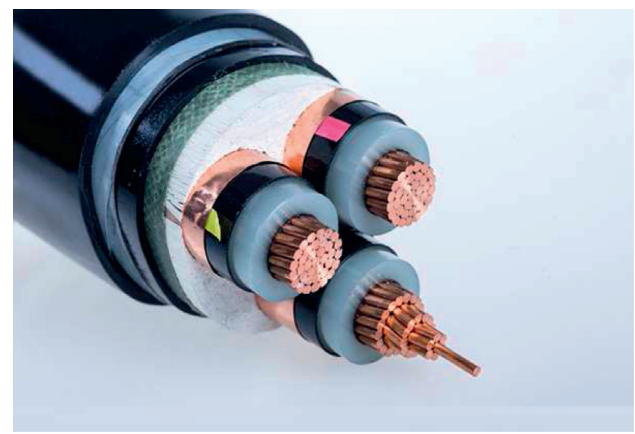

(d)

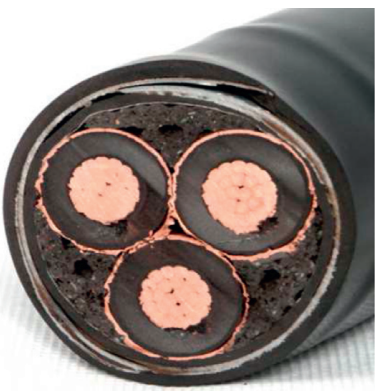

(e)

Figure 1: (a) Picture of cable laying; (b) photo of cable fire; (c) picture of cable insulation damage; (d) picture of structural analysis of threecore cable; (e) picture of cable radial section.

cable laying, cable fire, cable insulation damage, and structural damage.

To date, various studies were carried out on cable fire but primarily paid attention to the prevention, identification, and disaster reduction of power cable fire. Wang et al. investigated the performance of both fireproof cable tray and fire penetration prevention material and proposed that the performance of fire penetration prevention material is quite better than that of fireproof cable tray [12]. Pascal et al. investigated the ability of the FLASH-CAT model to predict the HRR for such configuration and proposed a video fire analysis method [13]. Zheng et al. studied the live combustion of power cable, evaluated the development process of the current numerical model of live combustion of power cable, and highlighted the fact that the current numerical simulation model of power cable fire is primarily concerned with the dynamic process after the fire [14]. Huang et al. investigated the vertical spread of cable fire in restricted space and proposed a jet temperature prediction for vertical cable fire that can estimate the harm of vertical spread of cable fire [15]. Zhang and Zhao mastered the changing rules of temperature and smoke in the fire process and highlighted the fact that the maximum ceiling temperature and the distributions of smoke are related to fire 
sealing and ventilation mode, by numerically simulating the smoke flow direction and temperature in the utility tunnel cable fire's development process [16]. There exists no detailed research on the very early detection and prediction of internal-caused cable fire.

Following the different fire sources, power cable fire is often split into internal-caused fire and external-caused fire. External-caused fire occurs when a cable is pushed to burn due to the activity of an external heat source. A cable fire caused by the high heat exceeding the ignition point of insulating material generated by the cable itself is known as the internal-caused fire [17]. Protective layers such as the insulation layer and the sheath layer surround the core conductor of power cables. The cable core temperature should be kept within the temperature range that insulating material can tolerate for an extended period of time. The high temperature of the core conductor would damage the insulating medium's stability, diminish insulation capacity, and readily form electrical trees, resulting in leakage, short circuits, and internal cable fire $[18,19]$. The highest working temperature of $\mathrm{XLPE}$ cable core is $90^{\circ} \mathrm{C}$. When the temperature is higher than $137^{\circ} \mathrm{C}$, there is a risk of cable internal-caused fire. At this time, the cable is in the very early stage of internal-caused fire [20]. It could be illustrated that the abnormal temperature rise of cable core in an internal-caused fire makes it possible to detect the fire in the very early stage.

Using the existing methods, it becomes difficult to measure the temperature of cable core conductor directly when the cable is running with electricity [21-23]. Therefore, precise assessment of the cable core's transient temperature is critical for early detection and forecast of cable fires caused by internal causes. There are two types of approaches that are widely used for calculating cable core temperature: analytical and numerical methods [24-26]. To calculate the cable core temperature, some researchers utilize a finite element model based on a numerical technique. However, the finite element model has a large amount of calculation, the accuracy would be influenced by the structure division and mesh size, and the real-time performance is poor, so it is not suitable for engineering applications [27].

To attain the goal of detection and prediction of internalcaused fire in electric cable and decrease the risk of cable fire, the objectives of this work are twofold: constructing an algorithm model for calculating the core temperature from the surface temperature of the outer sheath of cable; verifying the feasibility of the algorithm model in the very early detection of cable internal-caused fire by experiment. We present a trisection transient thermal circuit model based on the radial section structure of three-core cable to reduce the complexity of the model and establish a transient thermal circuit model algorithm to calculate the core temperature from the surface temperature of the outer sheath of cable in this study. Subsequently, we optimize the algorithm model by layering method for decreasing the influence of the internal temperature gradient within the cable material and the error of the algorithm model. Finally, a cable internalcaused fire experiment is conducted to verify the feasibility of the algorithm model in the very early detection and prediction of cable internal-caused fire.

\section{Theoretical Algorithm Model}

2.1. Transient Thermal Circuit Model. This paper takes the three-core power cable as the research object to investigate the corresponding relationship between the core temperature and the surface of outer sheath temperature and uses a three-core XLPE power cable as an example. Figure 2 depicts the structure. Considering that the diameter of the radial section is much smaller than the length of the power cable and the cable core has good thermal conductivity, the axial heat transmission of the power cable is not considered. Because the three-core power cable's radial sections are distributed in a triangle, radial thermal transfer is varied at different angles, and temperatures of the outer sheath surface are different. Assuming that the febrile responses of the three core lines of the cable are the same, the shortest path of thermal conduction on the radial section is investigated, and the temperature at the position shown at point "a" in Figure 2 is chosen as the surface temperature of the cable's outer sheath [27-31].

Accurate estimation of the transient temperature of cable core is the key to the very early identification and prediction of internal-caused fire in a cable, so a transient thermal circuit model is constructed based on the microstructure thermal transfer theory to examine the dynamic thermal transfer process of cable. The heat conduction stage in which the cable's internal heat is carried outward but has not yet reached equilibrium is referred to as transient thermal transfer of power cable. Each cable layer is treated as the cylinder wall, and the cylinder wall is also separated into microstructure, so that the cable's transient thermal circuit model can be established. According to the Fourier thermal transfer law, the thermal passage through the unit cross section per unit time is proportional to the area of the unit cross section and the temperature gradient in the direction of the vertical cross section. Then, the thermal $\mathrm{d} Q$ passing through the area of $\mathrm{d} A$ microstructure is shown in

$$
\mathrm{d} Q=-R \cdot \frac{\partial t}{\partial x} \mathrm{~d} A
$$

According to (1), the minus sign shows the direction of thermal transfer and $R$ represents thermal resistance. Take the three-core cable sheath per unit length as an example; its longitudinal section radius is $r$ and $c$ is specific thermal capacity. Assume the microstructure's thickness is $\mathrm{d} r$. The volume is $\mathrm{d} V$; the thermal inflow and outflow in time $\mathrm{d} \tau$ are $\mathrm{d} Q_{i}$ and $\mathrm{d} Q_{0}$, respectively; and the $\mathrm{d} Q_{p}$ is thermal generated by itself. Equation (2) depicts the temperature rise $\Delta t$ of the microstructure.

$$
\Delta t=\frac{\mathrm{dQ}_{i}+\mathrm{d} Q_{p}-\mathrm{d} Q_{0}}{c \cdot d V} .
$$

In (2), $d V=2 \pi r \cdot d r$; the thermal outflow is shown in

$$
\mathrm{dQ}_{0}=R \cdot \frac{\partial t}{\partial x} \cdot \mathrm{d} A \cdot \mathrm{d} \tau .
$$

In (3), $\mathrm{d} A=2 \pi r$. Equation (3) can be substituted into (2). 


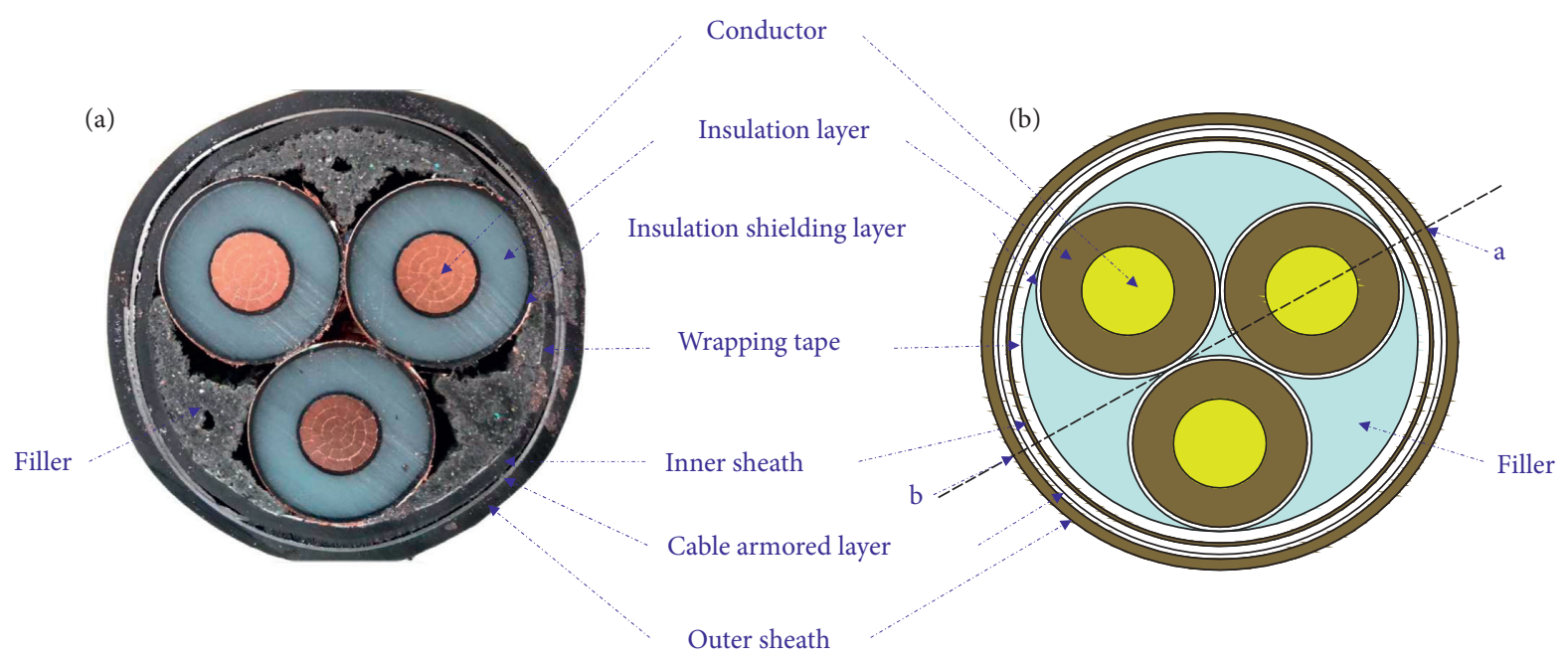

FIgURE 2: (a) Picture of cable radial section; (b) schematic diagram of cable radial section.

$$
\frac{\mathrm{d} Q_{i}}{\mathrm{~d} \tau}+\frac{\mathrm{d} Q_{p}}{\mathrm{~d} \tau}=2 \pi r \cdot R \frac{\partial t}{\partial r}+\frac{2 \pi r c \cdot \mathrm{d} r \cdot \Delta t}{\mathrm{~d} \tau} .
$$

If $P_{i}=\left(\mathrm{d} Q_{i} / \mathrm{d} \tau\right)$ and $P_{p}=\left(\mathrm{d} Q_{p} / \mathrm{d} \tau\right)$, (4) can be rewritten as

$$
P_{i}+P_{p}=2 \pi r \cdot R \frac{\partial t}{\partial r}+\frac{2 \pi r c \cdot \mathrm{d} r \cdot \Delta t}{\mathrm{~d} \tau} .
$$

Equation (5) is a cable sheath distributed parameter transient thermal circuit model. $2 \pi r \cdot R(\partial t / \partial r)$ shows the heat flowing through thermal resistance $P_{r}$; $(2 \pi r c \cdot \mathrm{d} r \cdot \Delta t / \mathrm{d} \tau)$ is the heat flowing through the heat capacity $P_{c}$. The microstructure transient thermal circuit model represented by (5) is depicted in Figure 3.

As an example, consider the cable sheath's distributed parameter thermal circuit model. The model can be applied to other layers of the power cable. Assuming the thermal capacity of each layer of the cable, the transient thermal circuit model of the power cable (YJV22-6/10 $\mathrm{kV}^{-3} \times 50$ ) is established, as depicted in Figure 4. Each layer of the cable's material is considered a layer of thermal resistance, and adjacent layers with the same thermal resistivity are grouped together. The cable's three core conductors have the highest and identical temperature, and their thermal resistance and thermal loss power are in parallel; as a result, the cores of the cable are the starting point of the thermal circuit, and the three cores are grouped together as a node. The insulation shielding layer of the three core lines is classified as the second node in the thermal circuit model, the armored layer as the third node, and the surface of outer sheath of the cable as the fourth node. In order to facilitate the calculation of thermal circuit model, it uses the following assumptions:

(1) The cable's material properties are stable, and its parameters are time-independent.

(2) Each layer of the cable is tightly bonded with no contact thermal resistance.
(3) The metal material has no thermal resistance.

(4) The cable's febrile response is uniform, and the heating power of the three cores of the cable is the same.

In Figure $4, P_{c}, P_{d}, \lambda_{2} P_{c a}$, and $\lambda_{2} P_{c}$ are the thermal loss power of core conductor, insulation layer, insulation shielding layer, and armored layer of cable, respectively; $C_{1}^{\prime}, C_{1}^{\prime \prime}, C_{2}^{\prime}, C_{4}^{\prime}$, and $C_{5}^{\prime}$ are the core conductor's thermal capacity, insulation layer, insulation shielding layer, armored layer, and outer sheath of the cable; $C_{3}^{\prime}$ is the cable filler's thermal capacity, wrapping tape, and inner sheath; $\theta_{1}, \theta_{2}$, and $\theta_{3}$ show the temperature of core conductor, insulation shielding layer, and armored layer of cable; $\theta_{0}$ indicates the surface temperature of outer sheath of the cable; $R_{1}$ and $R_{3}$ are the symbols of thermal resistance of cable insulation layer and cable outer sheath; and $R_{2}$ depicts the thermal resistance of cable filler, wrapping tape, and inner sheath. According to the principle that the total thermal does not vary, the parallel branch is equivalent to the series branch, and the cable's transient thermal circuit model is also simplified. The total heat flux on the left side of the thermal resistance of the insulation layer is $3 P_{c}+3 P_{d}$, the total heat flux on the right side of the thermal resistance of the insulation layer is $3 \lambda_{1} P_{c}$, and the thermal resistance of the insulation layer is $R_{1} / 3$. Then, the thermal circuit model is simplified, as illustrated in Figure 5.

In Figure $5, C_{1}=3 C_{1}^{\prime}+3 C_{1}^{\prime \prime}, P_{1}=3 P_{c}+3 P_{d}, P_{2}=3 \lambda_{1} P_{c}$, $C_{2}=3 C_{2}^{\prime}+C_{3}^{\prime}, \quad P_{3}=3 \lambda_{2} P_{c}, \quad C_{3}=C_{4}^{\prime}+C_{5}^{\prime}$. The transient thermal circuit model is identical to the structure of the circuit. Each portion of the cable has a heat loss power that is comparable to the power supply; the heat flux, temperature difference, thermal resistance, and thermal capacity are regarded as current, voltage difference, resistors, and capacitance, respectively, and each part's thermal capacity is comparable to its capacitance. The equations of the simplified transient thermal circuit model are illustrated below. 

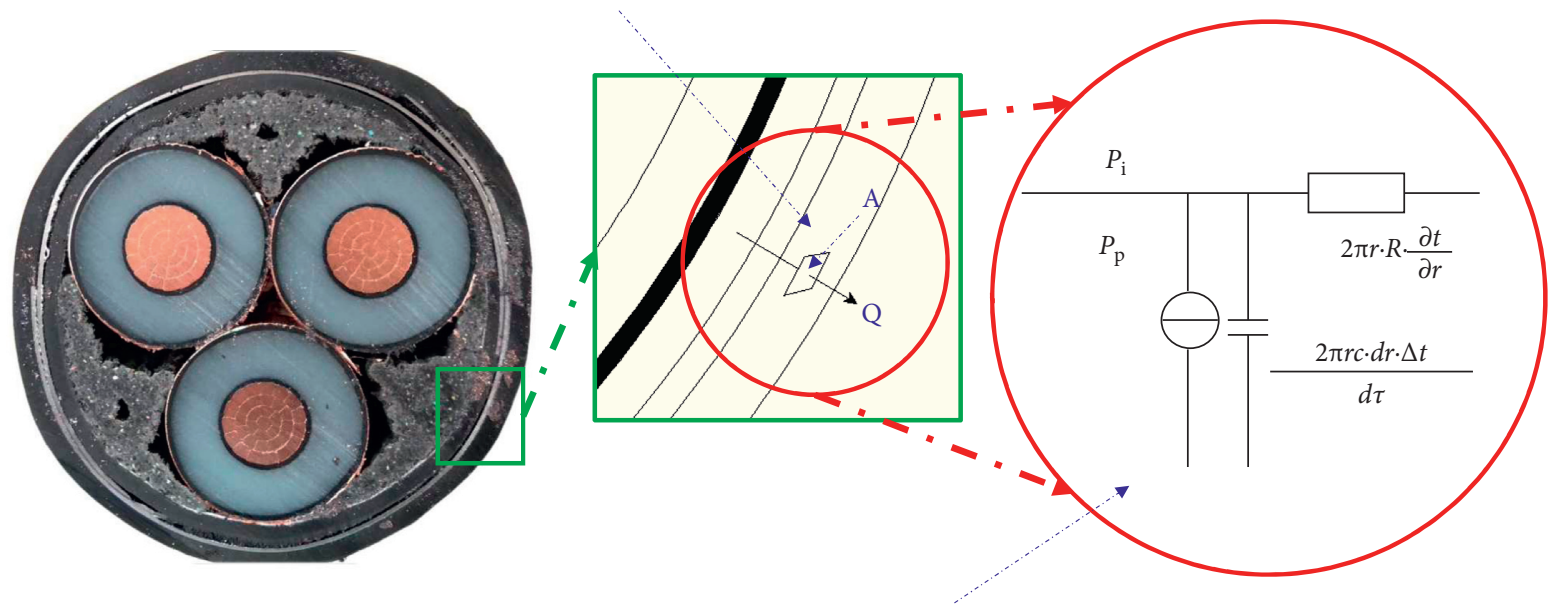

Micro-structure transient thermal circuit model

FIgURE 3: Transient thermal circuit model of cable sheath with microelement distributed parameters.

$$
\left\{\begin{array}{l}
C_{1} \frac{\mathrm{d} \theta_{1}}{\mathrm{~d} t}+\frac{3 \theta_{1}}{R_{1}}-\frac{3 \theta_{2}}{R_{1}}=P_{1}, \\
-\frac{3 \theta_{1}}{R_{1}}+C_{2} \frac{\mathrm{d} \theta_{2}}{\mathrm{~d} t}+\left(\frac{3}{R_{1}}+\frac{1}{R_{2}}\right) \theta_{2}-\frac{\theta_{3}}{R_{2}}=P_{2} \\
-\frac{\theta_{2}}{R_{2}}+C_{3} \frac{\mathrm{d} \theta_{3}}{\mathrm{~d} t}+\left(\frac{1}{R_{2}}+\frac{1}{R_{3}}\right) \theta_{3}-\frac{\theta_{0}}{R_{3}}=P_{3} .
\end{array}\right.
$$

In (6), $t$ indicates time. Equation (6) is organized into matrix form, as shown in the following equation:

$$
\dot{\boldsymbol{\theta}}=\mathbf{A} \boldsymbol{\theta}+\mathbf{B P} .
$$

If $\theta\left(t_{0}\right)=\beta$, then (7)'s solution is

$$
\boldsymbol{\theta}(t)=e^{\mathbf{A}\left(t-t_{0}\right)} \beta+\int_{t_{0}}^{t} e^{\mathbf{A}\left(t-t_{0}\right)} \mathbf{B} \mathbf{P} \partial \tau .
$$

According to (8),

$$
\begin{aligned}
& e^{A t}=\mathbf{E}+\mathbf{A} t+\frac{1}{2 !} \mathbf{A}^{2} t^{2}+\frac{1}{3 !} \mathbf{A}^{3} t^{3}+\cdots=\sum_{k=0}^{\infty} \frac{1}{k !} \mathbf{A}^{k} t^{k}, \\
& \dot{\boldsymbol{\theta}}=\left[\begin{array}{lll}
\frac{\mathrm{d} \theta_{1}}{\mathrm{~d} t} & \frac{\mathrm{d} \theta_{2}}{\mathrm{~d} t} & \frac{\mathrm{d} \theta_{3}}{\mathrm{~d} t}
\end{array}\right]^{T}, \\
& \boldsymbol{\theta}=\left[\begin{array}{lll}
\theta_{1} & \theta_{2} & \theta_{3}
\end{array}\right]^{T} \text {, } \\
& \mathbf{A}=\left[\begin{array}{ccc}
a_{1,1} & a_{1,2} & 0 \\
a_{2,1} & a_{2,2} & a_{2,3} \\
0 & a_{3,2} & a_{3,3}
\end{array}\right]
\end{aligned}
$$

In matrix $\mathbf{A}, a_{1,1}=-3\left(C_{1} R_{1}\right)^{-1}, \quad a_{1,2}=3\left(C_{1} R_{1}\right)^{-1}$, $a_{2,1}=3\left(C_{2} R_{1}\right)^{-1}, a_{2,2}=-C^{-1}\left(3 R^{-1}+R^{-1}\right), a_{2,3}=\left(C_{2} R_{2}\right)^{-1}$, $a_{3,2}=\left(C_{3} R_{2}\right)^{-1}, a_{3,3}=-C_{3}^{-1}\left(R_{2}^{-1^{1}}+R_{3}^{-1}\right)^{2}$.

$$
\begin{aligned}
& \mathbf{B}=\left[\begin{array}{ccc}
C_{1}^{-1} & 0 & 0 \\
0 & C_{2}^{-1} & 0 \\
0 & 0 & C_{3}^{-1}
\end{array}\right] \\
& \mathbf{P}=\left[\begin{array}{lll}
P_{1} & P_{2} & P_{X}
\end{array}\right]^{T}
\end{aligned}
$$

In (11), $P_{X}=\theta_{0} R_{3}^{-1}+P_{3}$. According to the surface temperature of the cable's outer sheath, the temperature of the cable core is calculated.

2.2. Trisection Transient Thermal Circuit Model. The transient thermal circuit model is complex because the impacts of mutual thermal transfer and respective external thermal transfer of three cable cores must be considered. In order to make the model less complicated, the radial section of cable is separated into three equal parts, and each part is equivalent to a single-core cable, as illustrated in Figure 6. Thermal is transported from core to point "a" on the surface of the outer sheath through insulation layer, insulation shielding layer, wrapping tape, inner sheath, armored layer, and outer sheath. Because the filler is not on the quickest thermal transfer path, only the thermal capacity of the filler is calculated instead of its thermal resistance. As shown in Figure 7, a trisection transient thermal circuit model from core conductor to point "a" on the surface of the outer sheath is created.

In Figure $7, P_{1}^{\prime}, P_{1}^{\prime \prime}, P_{2}^{\prime}$, and $P_{4}^{\prime}$ mean the thermal loss power of core conductor, insulation layer, insulation shielding layer, and armored layer of cable; $\theta_{1}^{\prime}, \theta_{3}^{\prime}$, and $\theta_{4}^{\prime}$ are temperatures of core conductor, insulation shielding layer, and armored layer of cable; $\theta_{2}^{\prime}$ is the temperature of the cable insulation layer's outer skin; $\theta_{5}^{\prime}$ shows the surface temperature of the outer sheath of the cable; $R_{1}^{\prime}$ and $R_{4}^{\prime}$ indicate the thermal resistance of the cable insulation layer and outer sheath; and the thermal resistance of the cable wrapping tape and inner sheath is denoted by $R_{2}^{\prime}$. 


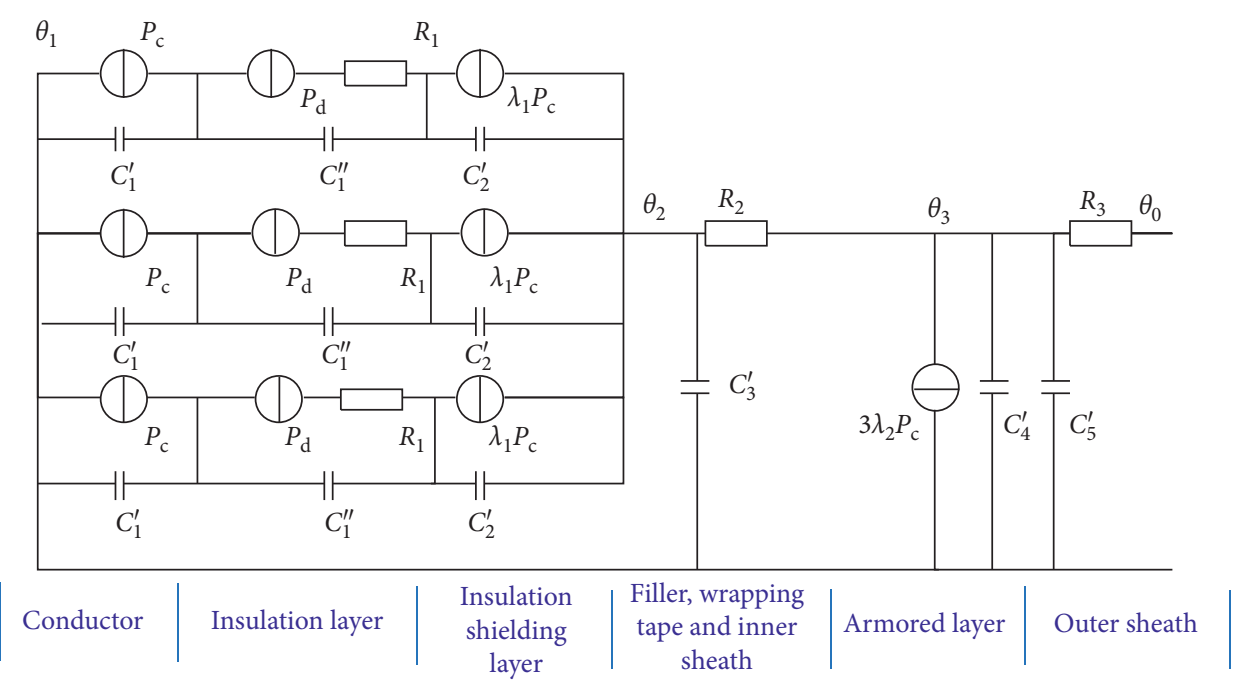

Figure 4: Transient thermal circuit model of power cable.

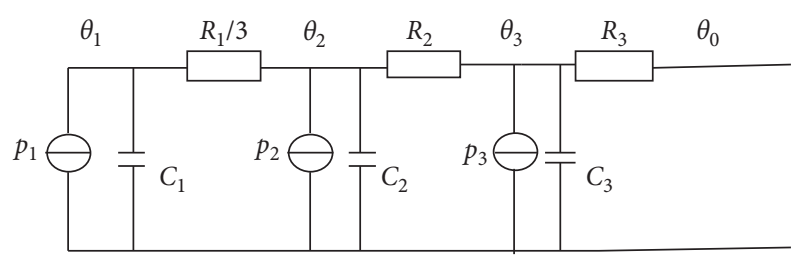

FIGURE 5: Modeling of a power cable's transient thermal circuit simplified.

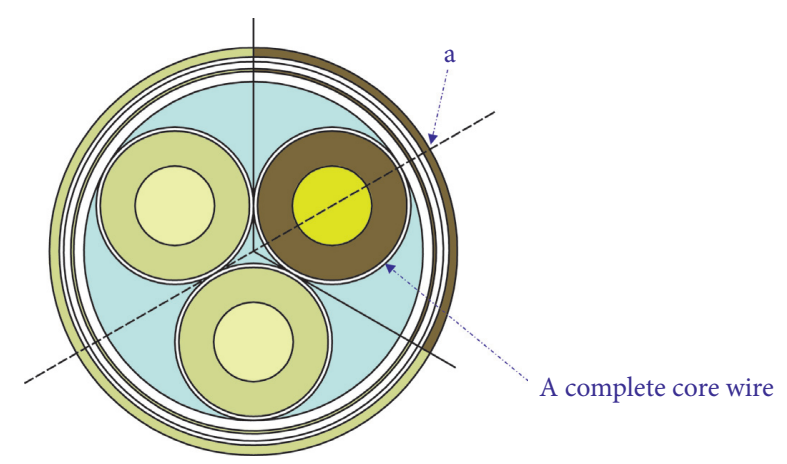

Figure 6: Schematic diagram of trisection of cable radial section.

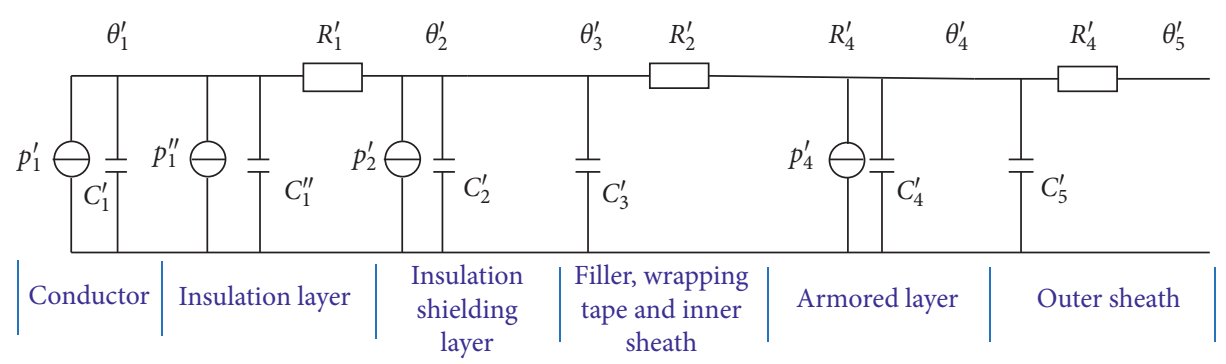

Figure 7: Thermal circuit model of power cable temperature field.

2.3. Thermal Circuit Model Layered Optimization. The thermophysical properties of the cable body material are important factors that have a significant impact on the calculation accuracy of the thermal circuit model algorithm. The thermal diffusivity, for example, in a material is a measure of the thermal transfer rate inside the material, indicative of the thermal change inside the material. 


$$
a=\frac{\lambda}{\rho c} .
$$

The parameters $a, \rho, \lambda$, and $c$ in (12) represent thermal diffusivity, density, thermal conduction coefficient, and specific thermal capacity of the material. The thermal diffusivity is mostly determined by the parameter characteristics of the material, which is directly proportional to the thermal conduction coefficient and inversely proportional to the product of density and specific thermal capacity. Materials having high thermal conduction coefficient have better thermal conductivity. As a result, the temperature difference inside the material is minimal. The insulation layer, inner sheath, and outer sheath all have a low thermal conduction coefficient, resulting in large internal temperature gradients. The insulation layer, inner sheath, and outer sheath all have a low thermal conduction coefficient, resulting in large internal temperature gradients. If the temperature of the innermost layer of material is used to represent the temperature of the entire layer of material in the calculation, it will undoubtedly result in a significant calculation error of the algorithm model, and the calculation error is positively associated with the temperature gradient. Therefore, a layered trisection transient thermal circuit model of power cable in which insulation layer, inner sheath, and outer sheath are layered is constructed, to reduce the influence of the internal temperature gradient within the cable material. The insulation layer, inner sheath, and outer sheath of the cable are separated into $L$ layers, $M$ layers, and $N$ layers, respectively, and $L, M$, and $N$ are positive integers. The layered trisection transient thermal circuit model is depicted in Figure 8.

In Figure 8, $C_{11}^{\prime} \sim C_{1 L}^{\prime}$ show the thermal capacity of each layer of the cable insulation layer; the thermal loss power of each layer of the cable insulation layer is indicated by $P_{11}^{\prime} \sim P_{1 L}^{\prime} ; R_{11}^{\prime} \sim R_{1 L}{ }^{\prime}$ denote the thermal resistance of each layer of the cable insulation layer; $R_{3}^{\prime}$ indicates the thermal resistance of the cable wrapping tape; $C_{41}{ }^{\prime} \sim C_{4 M}{ }^{\prime}$ denote the thermal capacity of each layer of the cable inner sheath; $P_{41}^{\prime} \sim P_{4 M}^{\prime}$ are the symbols of thermal loss power of each layer of the cable inner sheath; $R_{41}{ }^{\prime} \sim R_{4 M}{ }^{\prime}$ are the representations of thermal resistance of each layer of the cable inner sheath; the symbol $P_{5}^{\prime}$ indicates the thermal loss power of the cable armored layer; $C_{61}{ }^{\prime} \sim C_{6 M}{ }^{\prime}$ represent the thermal capacity of each layer of the outer sheath of the cable; $P_{61}^{\prime} \sim P_{6 M}^{\prime}$ depict the power loss of each layer of the outer sheath of the cable; $R_{61}^{\prime} \sim R_{6 M}{ }^{\prime}$ represent the thermal resistance of each layer of the outer sheath of the cable; and ${ }_{\theta}^{0}$ is the surface temperature of the outer sheath of the cable. As indicated in Figure 9, the multilayer thermal circuit model is integrated and simplified.

The node equations of the thermal circuit model are listed, and the following equations are obtained, based on similar properties of the thermal circuit model and the circuit.

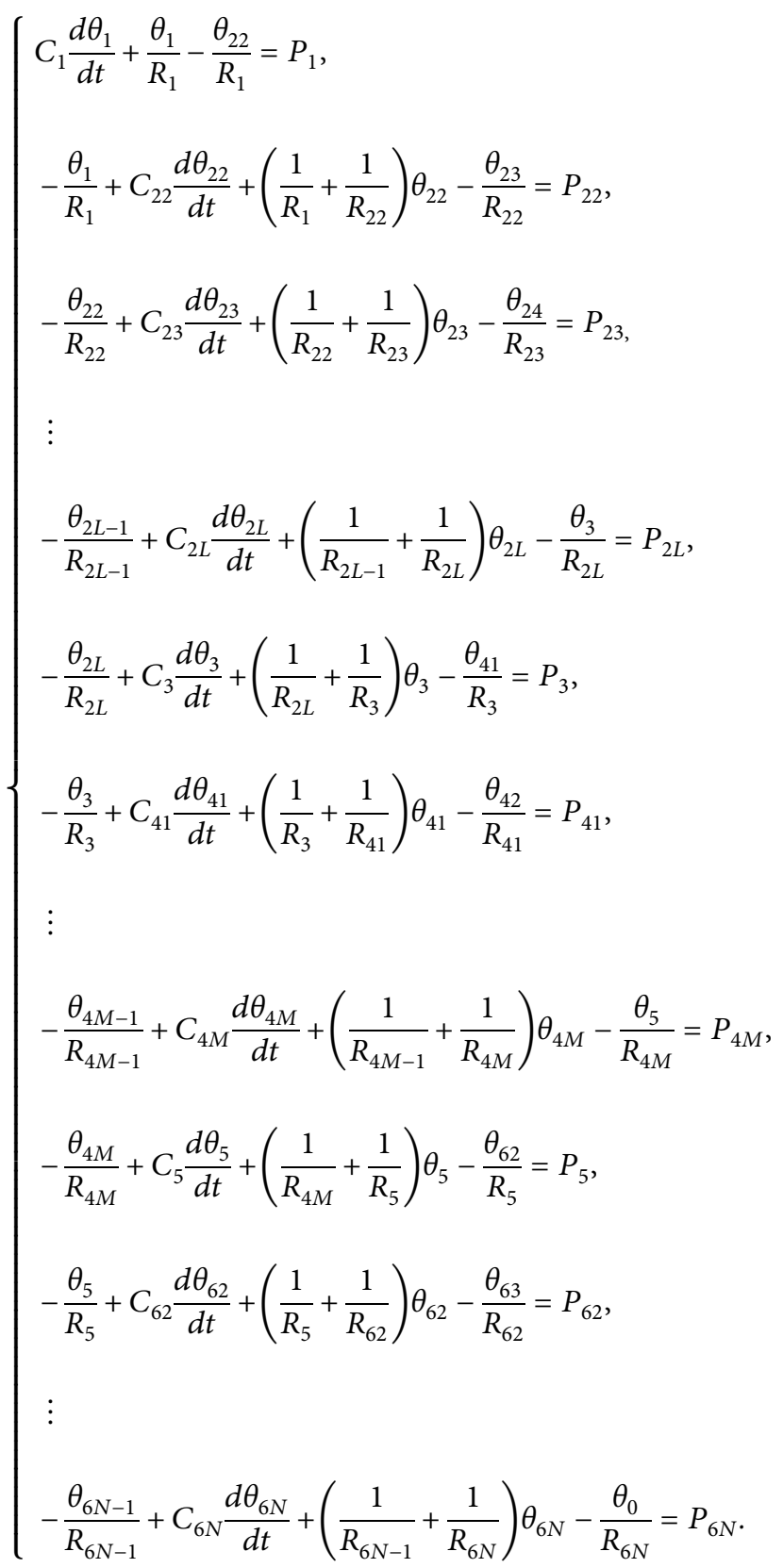

In (13), $t$ indicates time; the other variables are shown in Figure 9. The equation is converted into matrix, and the cable core temperature is calculated using the same method as in (7).

\section{Experimental Test}

3.1. Experimental Apparatus and Tested Cable. The cable internal-caused fire experimental platform which includes a current increasing module and a temperature monitoring module is powered by $380 \mathrm{~V}$ AC. The current raising module supports low-voltage and high current output through the use of an automatic voltage regulator and current raising 


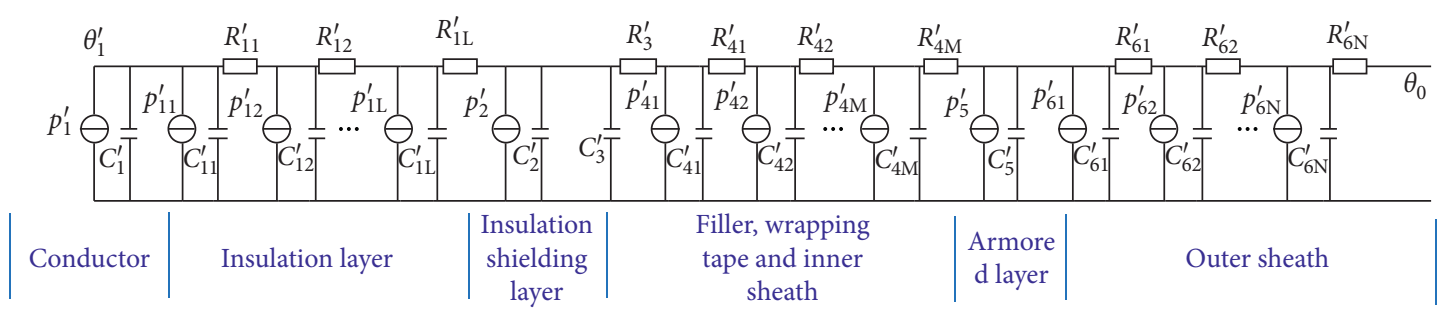

Figure 8: Layered trisection transient thermal circuit model of power cable.

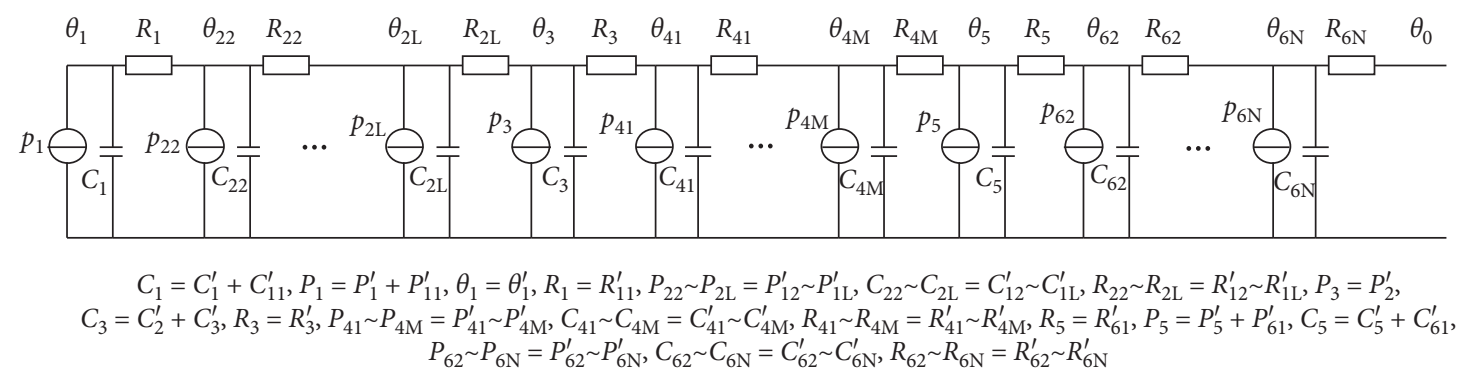

FIgURE 9: Simplification of layered trisection transient thermal circuit model of power cable.

device. The temperature measurement module contains realtime collection of 16 channels of temperature data. By connecting external thermocouple sensors, temperature data from each point of the tested cable can be collected and recorded [32]. Picture and system diagram of experimental platform are shown in Figure 10. The following are the main technical parameters: output current range, 0-1000 A; temperature measurement range, $-80 \sim+500^{\circ} \mathrm{C}$; temperature measurement error range, $\pm 0.1^{\circ} \mathrm{C}$.

In this experiment, the XLPE power cable (YJV22-6/ $\left.10 \mathrm{kV}^{-3} \times 50\right)$ is selected as the tested cable. On the radial part of the cable, the three core lines are symmetrically arranged in a triangle. The structure of the cable includes core conductor, insulation layer, insulation shielding layer, filler, wrapping tape, inner sheath, cable armored layer, and outer sheath. Table 1 lists the cable parameters.

\subsection{Experimental Processes}

3.2.1. Experiment Preparation. Three hours before the test, the air conditioner was adjusted to $20^{\circ} \mathrm{C}$ to guarantee that the experimental environment and the starting temperature of the cable under test were both $20^{\circ} \mathrm{C}$. The tested cable was connected with the cable internal-caused fire test platform. One end of cable is connected to large current output port of test platform, and the other end is short-circuited.

3.2.2. Thermocouple Installation. To monitor the temperature of the tested cable, thermocouple sensors are placed on the surface of the outer sheath and core conductor. Three holes in the cable are drilled to expose the core conductor, and thermocouple sensors are installed in these holes to measure temperature of core conductor of cable. Thermocouple sensors are pasted within $5 \mathrm{~cm}$ from drilling position on the surface of cable outer sheath to measure surface temperature of cable outer sheath. Figure 11 depicts a picture and structural schematic of a thermocouple installation.

3.2.3. Loading Experimental Current. In this experiment, continuous currents of $180 \mathrm{~A}$ and $380 \mathrm{~A}$ are used, and threephase current is balanced. A $180 \mathrm{~A}$ experimental current is utilized to mimic the normal functioning condition of the cable, and then $380 \mathrm{~A}$ step currents are used to model the fault currents of the cable. At first, experimental current is set to $180 \mathrm{~A}$ to simulate normal working state of cable under test. After temperatures of core conductor and surface of outer sheath tend to be stable, output current of cable internal-caused fire experimental platform is adjusted to $380 \mathrm{~A}$ for stimulating the fault state of cable. When the fault simulation current is applied on the cable, the temperature of cable core rises and slowly exceeds the maximum allowable temperature of $90^{\circ} \mathrm{C}$. The experiment is terminated if the observed temperature of the cable core exceeds $137^{\circ} \mathrm{C}$. Figure 12 depicts the experimental current.

\section{Results and Discussion}

4.1. Cable Core Temperature and Outer Sheath Surface Temperature. Under normal and fault circumstances, the experiment replicates the change in cable core temperature and outer sheath surface temperature. Both the core temperature and the surface temperature of the outer sheath of the cable begin to rise, and the core temperature is greater than the surface temperature of the outer sheath of the cable, but the rate of temperature rise for both is very slow. When the load current is continuously loaded for about 2.8 hours, the temperature of the core and the surface of the outer sheath tend to remain steady. When a current of $380 \mathrm{~A}$ is applied, the core temperature and the surface temperature of the outer sheath of the cable begin to rise again and the 


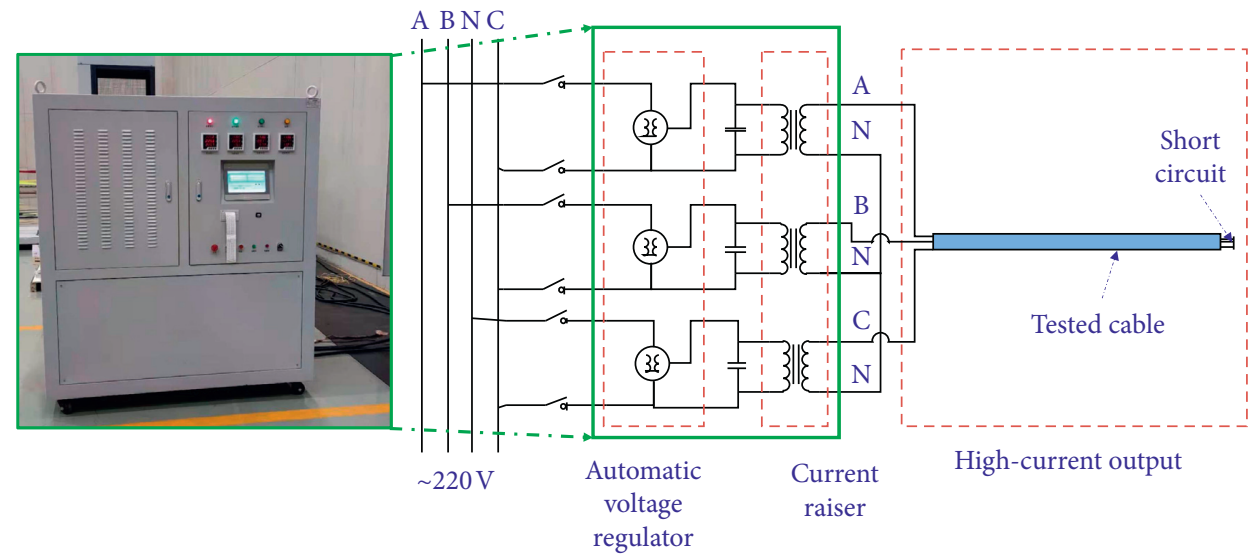

FIGURE 10: Picture and system diagram of experimental platform.

Table 1: Parameters of layers of YJV22 6/10 kV cable.

\begin{tabular}{lcccc}
\hline Structure & Inner diameter $(\mathrm{mm})$ & Outer diameter $(\mathrm{mm})$ & Thermal conductivity $\left(\mathrm{W}(\mathrm{km})^{-1}\right)$ & $\begin{array}{c}\text { Volumetric heat capacity } \\
\left(10^{4}\left(\mathrm{JK}^{-1} \mathrm{~m}^{-3}\right)\right)\end{array}$ \\
\hline Conductor & & 8.6 & 400 & 434.14 \\
Insulation layer & 8.6 & 17.6 & 0.32 & 303.12 \\
Insulation shielding layer & 17.6 & 19.2 & 400 & 434.14 \\
Wrapping tape & 44.4 & 45.4 & 0.2 & 196.00 \\
Inner sheath & 45.4 & 49.2 & 0.2 & 124.2 \\
Cable armored layer & 49.2 & 50.2 & 48 & 372.88 \\
Outer sheath & 50.2 & 55.6 & 0.2 & 124.2 \\
\hline
\end{tabular}

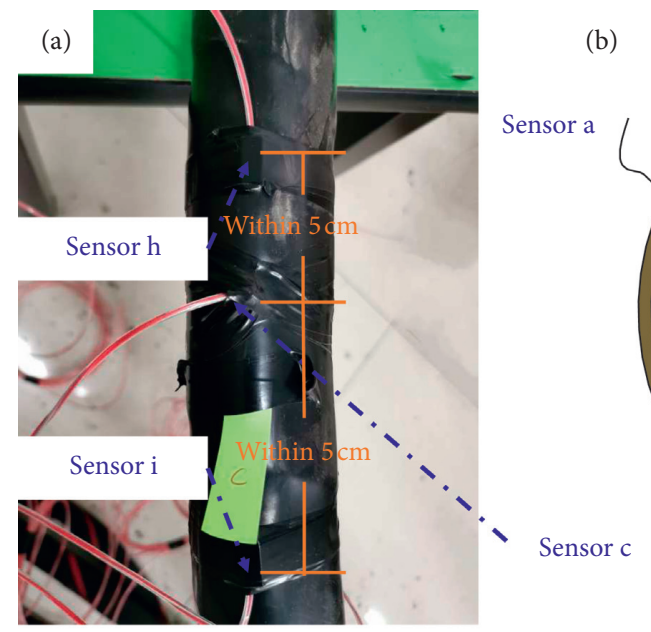

(b)

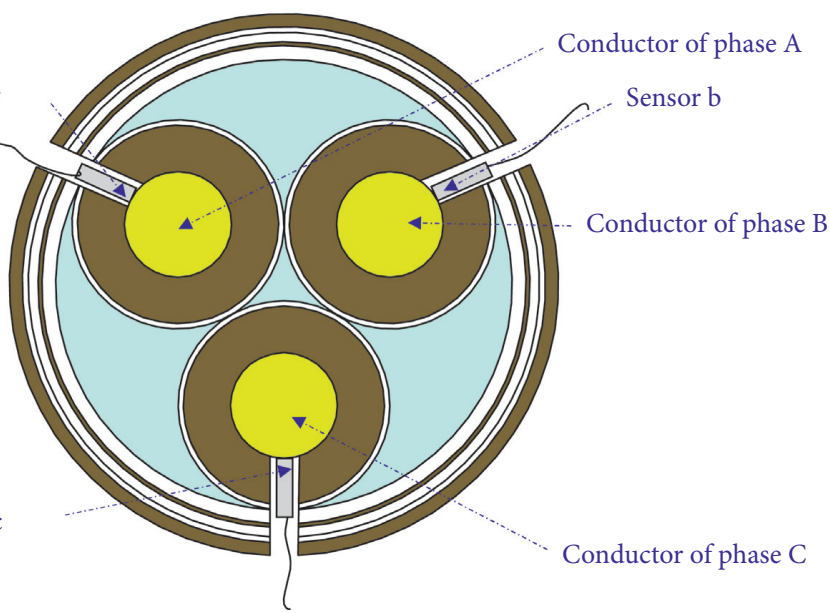

Figure 11: (a) Picture of thermocouple installation; (b) schematic diagram of thermocouple installation.

temperature rise of the outer sheath surface of the cable is lagging relative to the cable core; the temperature rise rate of outer sheath surface is less than that of the cable core. Figure 13 depicts the temperature change of the cable core and the surface temperature of the outer sheath.

\subsection{Verification of the Proposed Model by Experimental Data.} The current values and the surface temperatures of the outer sheath measured in the experiment are substituted into the transient thermal circuit model, and the core temperature of the cable is calculated. When the calculated value of cable core temperature is compared to the experimental observed value, it is discovered that the estimated value of cable core temperature is lower. The error analysis of the experimental and calculated values of the cable core temperature is shown in Table 2. Calculation error of the transient thermal circuit model rises as the load current, yet the typical relative and absolute errors are less than $10 \%$, and the average absolute errors are less than $10^{\circ} \mathrm{C}$. 


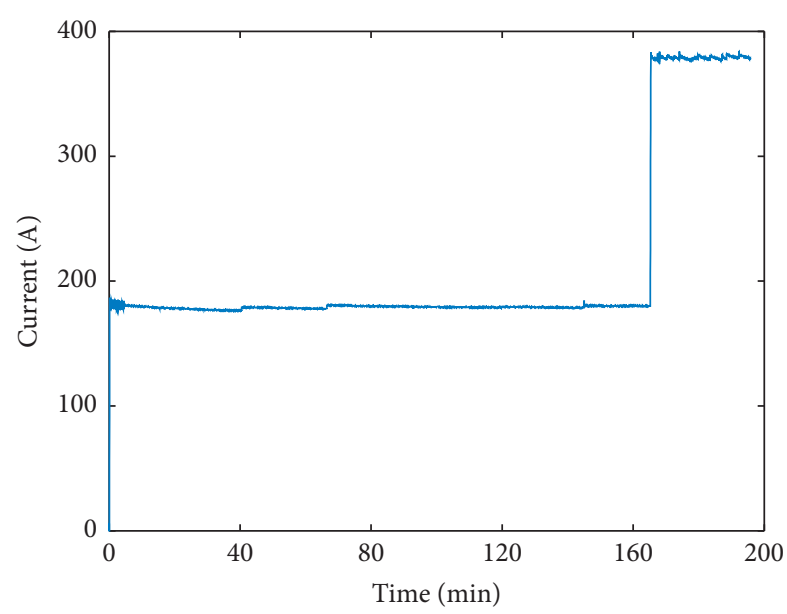

Figure 12: Cable current curve.

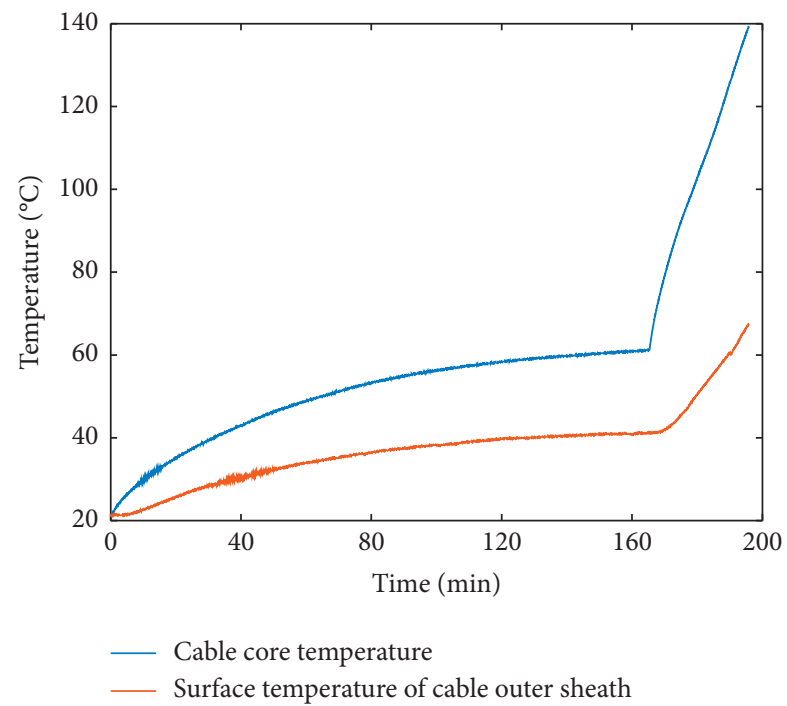

Figure 13: Change curve of cable core temperature and outer sheath surface temperature.

TABLE 2: Calculation error of transient thermal circuit model under various load currents.

\begin{tabular}{lcc}
\hline \multirow{2}{*}{ Simulative current (A) } & \multicolumn{2}{c}{ Average error } \\
& Relative error (\%) & Absolute error $\left({ }^{\circ} \mathrm{C}\right)$ \\
\hline 180 & -2.49 & -5.12 \\
380 & -7.98 & -7.82 \\
\hline
\end{tabular}

Similar to this, we plug the data in the experiment into trisection transient thermal circuit model and analyze the error between the calculated value and the experimental value. Table 3 shows the error analysis of experimental and estimated cable core temperature data. Calculation error of the trisection transient thermal circuit model is bigger as compared to the transient thermal circuit model and increases with the increase of the load current; the average absolute errors are less than $10^{\circ} \mathrm{C}$, while the average relative errors are still less than $10 \%$.
TABLE 3: Calculation error of trisection transient thermal circuit model under various load currents.

\begin{tabular}{lcc}
\hline \multirow{2}{*}{ Simulative current (A) } & \multicolumn{2}{c}{ Average error } \\
& Relative error (\%) & Absolute error $\left({ }^{\circ} \mathrm{C}\right)$ \\
\hline 180 & -3.74 & -7.73 \\
380 & -9.92 & -9.55 \\
\hline
\end{tabular}

The systematic measurement error, the contact thermal resistance, and the temperature gradient inside the material are the major causes of mistakes, with the temperature gradient being the most important component. Take insulation layer of cable as an example; it is assumed that the innermost temperature of the cable insulation layer is $\theta_{x}$, the outermost temperature is $\theta_{y}$, the inner diameter of the cable insulation layer is $d_{1}$, and the outer diameter is $d_{2}$, so its corresponding radius is $r_{1}=\left(d_{1} / 2\right)$ and $r_{2}=\left(d_{2} / 2\right)$. Equation (14) should be filled up using the above parameters.

$$
\frac{\mathrm{d}}{\mathrm{d} r}\left(r \frac{\mathrm{d} \theta}{\mathrm{d} r}\right)=0 .
$$

The following equation can be obtained by solving (14).

$$
\theta=\theta_{x}+\frac{\theta_{y}-\theta_{x}}{\ln \left(r_{2} / r_{1}\right)} \ln \frac{r}{r_{1}} .
$$

Take the derivative on both sides of (15).

$$
\frac{\mathrm{d} \theta}{\mathrm{d} r}=\frac{1}{r} \cdot \frac{\theta_{y}-\theta_{x}}{\ln \left(r_{2} / r_{1}\right)}
$$

From (16), temperature gradient is inversely proportional to the radius, the closer the thermal source, the greater the temperature gradient, and the greater the influence of layering on the calculation accuracy of the transient thermal circuit model. As a consequence, layered optimization of the thermal circuit model can decrease the impact of temperature gradient on calculation results while also increasing the model's calculation accuracy. Using the controlled variable method, the insulation layer, inner sheath, and outer sheath of the cable are calculated successively from 1 to 100 layers and compared with the measured core temperature of the experiment. Figure 14 shows the variation of computation error with the number of layers. It could be seen that the layered optimization of the algorithm model can effectively decrease the calculation error and the layered insulation layer holds a greater impact on the calculation accuracy of the algorithm model as compared to the other two layers.

Increasing the number of layers can reduce the calculation error of the model; however, if the number of layers is sufficient, the temperature gradient in each layer becomes extremely tiny. When this occurs, increasing the number of layers has minimal effect on computation accuracy and would increase the calculation amount of the model. Hence, the appropriate number of layers must be selected in the layering optimization of algorithm model. Because the thermocouple sensor's measurement precision is $0.1^{\circ} \mathrm{C}$ in 


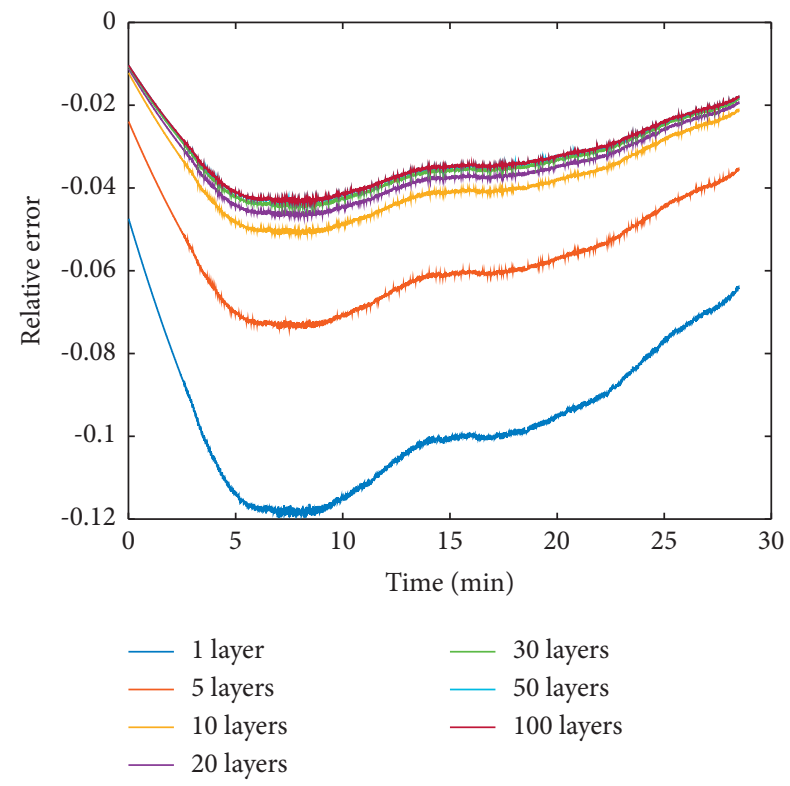

(a)

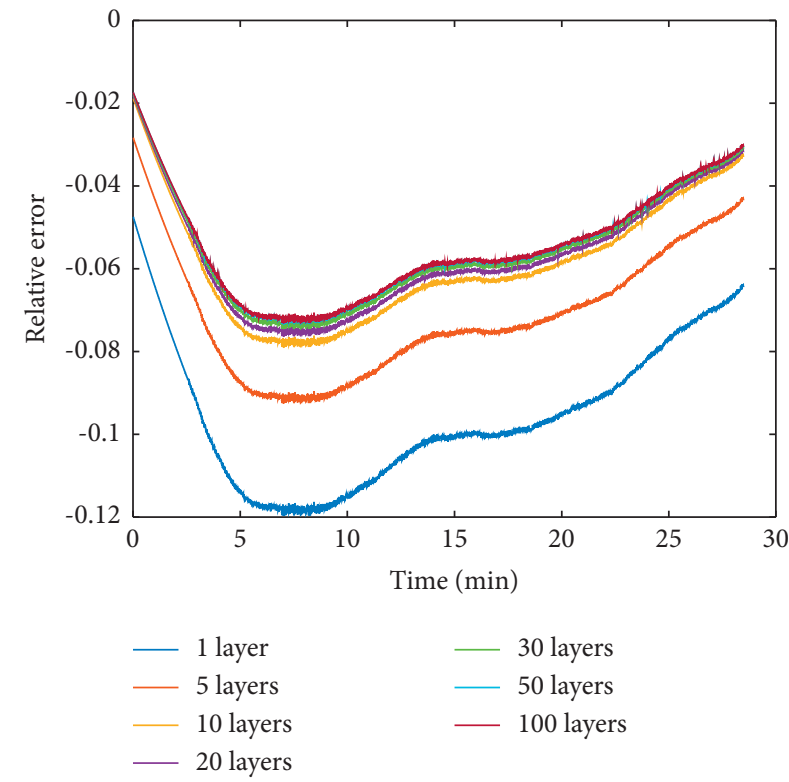

(b)

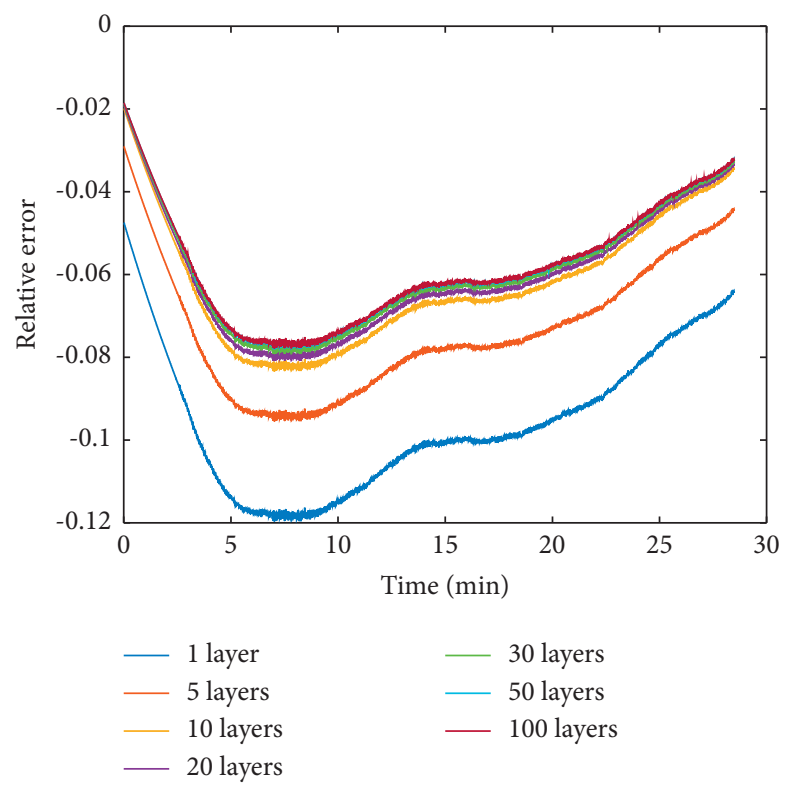

(c)

FIGURE 14: (a) Variation curve of relative error with the number of layers of insulation layer; (b) variation curve of relative error with the number of layers of inner sheath layer; (c) variation curve of relative error with the number of layers of outer sheath layer.

this experiment, the maximum value of the improved calculation accuracy value relative to the front stage layering is chosen to determine the appropriateness of the number of layers. When the maximum value approaches $0.1^{\circ} \mathrm{C}$, we believe that the number of layers at this level is the appropriate number of layers. As illustrated in Table 4, when the numbers of layers are 50, the maximum value approaches $0.1^{\circ} \mathrm{C}$. Thus, the numbers of layers of insulation, inner sheath, and outer sheath are all 50 in this study.

As a consequence, stacking the cable sheath can effectively minimize the trisection transient thermal circuit model's calculation circuit. When $\mathrm{L}=50, \mathrm{M}=50$, and $\mathrm{N}=50$, the relative error of the thermal circuit model algorithm is analyzed. The estimated core temperature has a maximum relative error of less than 2 percent with an average relative error of 1.08 percent, meeting the calculation requirements of extremely early detection and prediction of cable internalcaused fire.

4.3. Response Time of the Model. It can be seen from the above analysis that the calculated value of the cable core temperature is less than the experimental measurement value. When the temperature is $137^{\circ} \mathrm{C}$, the time difference between the calculated value and the measured value is 
TABLE 4: The maximum value of the increased calculation accuracy value relative to the front level layering.

\begin{tabular}{lccc}
\hline \multirow{2}{*}{ Number of layers } & \multicolumn{3}{c}{ Maximum value $\left({ }^{\circ} \mathrm{C}\right)$} \\
& Insulation layer & Inner sheath & Outer sheath \\
\hline 5 & 5.23 & 3.1 & 2.7 \\
10 & 1.81 & 1.36 & 1.15 \\
20 & 0.7 & 0.54 & 0.51 \\
30 & 0.2 & 0.16 & 0.16 \\
50 & 0.1 & 0.11 & 0.1 \\
100 & 0.01 & 0.021 & 0.021 \\
\hline
\end{tabular}

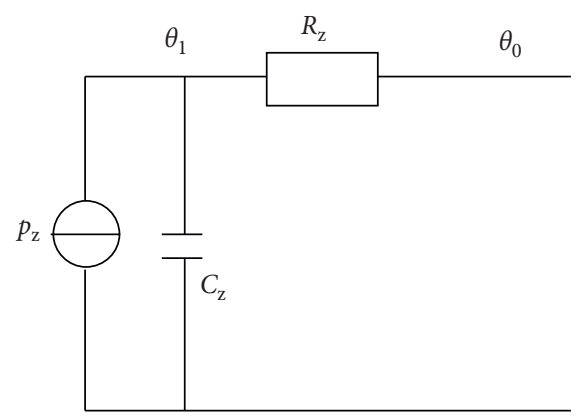

FIGURE 15: Equivalent first-order thermal circuit model of cable.

called the response time of detection and prediction. The response time of cable internal-caused fire early detection and prediction is an indicator to measure the rapidity of the model's response. The layered trisection transient thermal circuit model is equivalently combined into a first-order thermal circuit model of a single heat source, as shown in Figure 15.

According to the heat balance theory in heat transfer, the heat balance equation is established.

$$
P_{z}=C_{z} \frac{\mathrm{d} \theta_{1}}{\mathrm{~d} t}+\frac{\theta_{1}-\theta_{0}}{R_{z}} .
$$

Assuming that the initial temperature of the cable core when the fault current is loaded is $\theta_{1}^{0}$, the general solution of (17) is

$$
\begin{aligned}
\theta_{1} & =P_{z} R_{z}+\theta_{0}+\left(\theta_{1}^{0}-\theta_{0}-P_{z} R_{z}\right) e^{-\left(t / R_{z} C_{z}\right)}, \\
t & =R_{z} C_{z}\left(\ln \left(\theta_{1}^{0}-\theta_{0}-P_{z} R_{z}\right)-\ln \left(\theta_{1}-\theta_{0}-P_{z} R_{z}\right)\right) .
\end{aligned}
$$

The expression of $t$ is a function of time as

$t(\tau)=R_{z} C_{z}\left(\ln \left(\theta_{1}^{0}(\tau)-\theta_{0}(\tau)-P_{z} R_{z}\right)-\ln \left(\theta_{1}-\theta_{0}(\tau)-P_{z} R_{z}\right)\right)$,

where $t_{1}$ and $t_{2}$, respectively, indicate the time when the measured value and the calculated value reach $137^{\circ} \mathrm{C}$. $\mathrm{Re}-$ sponse time of cable internal-caused fire early detection and prediction is

$$
t_{Y}=t_{2}-t_{1} .
$$

In the formula, $\theta_{0}(\tau)$ is the surface temperature of the outer sheath of the cable at different times; $\theta_{1}^{0}(\tau)$ is the temperature of the cable core at different times; and $\theta_{1}$ is $137^{\circ} \mathrm{C}$. The response time of cable internal-caused fire early detection and prediction of the model is $148 \mathrm{~s}$ when the experimental current is $380 \mathrm{~A}$. The response time is less than 3 min, which meets the needs of cable internal-caused fire early detection and prediction.

\section{Conclusion}

Early detection and prediction technology of cable internalcaused fire may significantly minimize cable fire probability in tunnels and ensure cable tunnel safety. An algorithm model for estimating the core temperature from the surface temperature of cable outer sheath was developed in this work, and it was shown to be viable in the early detection of cable internal-caused fire by experiment. The main conclusions are as follows:

(1) Error analyses illustrate that the calculated value of cable core temperature is less as compared to the measured value. The reason is that the temperature of inner surface of the material has been chosen to calculate the thermal capacity of the material, leading to the calculated thermal capacity of each layer of material being greater than the actual thermal capacity.

(2) To solve the problem that the temperature of the cable core cannot be directly measured, a transient thermal circuit model has been suggested, so that the abnormal temperature rise characteristics of the cable core could be utilized for the very early detection and prediction of the cable internalcaused fire. The trisection transient thermal circuit model decreases the transient thermal circuit model's complexity while simultaneously increasing calculation error. It is noteworthy that the calculation errors of the two models are less than $10 \%$, which could cater to the needs of very early detection and prediction of internal-caused fire of cable.

(3) Layered optimization can lower the calculation error, but once the number of layers of cable material exceeds a certain order of magnitude, increasing the number of layers has a limited impact on the calculation accuracy of the model. The highest relative error of the estimated value of the model is less than 2 percent, and the average relative error is 1.08 percent in this article when the number of layers of cable insulation layer, inner sheath, and outer sheath is 50 layers.

(4) The response time of cable internal-caused fire early detection and prediction of the layered trisection transient thermal circuit model is less than $3 \mathrm{~min}$, which meets the needs of early detection and prediction of the cable internal-caused fire.

\section{Data Availability}

The data used to support the findings of this study are available from the corresponding author upon request. 


\section{Conflicts of Interest}

The authors declare that there are no conflicts of interest.

\section{References}

[1] Y. Liu and X. Zhao, "Research on harmful mechanism of approaching construction to urban cable tunnels and protective suggestion," Electric Power Survey and Design, vol. 8, pp. 22-28, 2021.

[2] B. Wu and P. A. N. G. Zhe, "Development status of intelligent inspection robots in power tunnel environment," Industrial Control Computer, vol. 34, no. 7, pp. 20-22, 2021.

[3] K. Liang, X. Hao, W. An, Y. Tang, and Y. Cong, "Study on cable fire spread and smoke temperature distribution in T-shaped utility tunnel," Case Studies in Thermal Engineering, vol. 14, Article ID 100433, 2019.

[4] L. I. U. Yang, J. Chen, L. I. Chenying, C. H. E. N. Hong, K. Liu, and X. I. E. Qiyuan, "Experimental study on the influence of intumescent fire-resistant coating on ignition characteristics of high-voltage power cables," Fire Safety Science, vol. 29, no. 4, pp. 214-221, 2020.

[5] Z. H. A. O. Jing, T. U. Haoxi, and Y. Chen, "220 KV and above voltage level city cable tunnel fire protection system design," in Proceedings of the International Conference On New Energy Science And Research (ICESR), pp. 463-468, Destech Publicat Inc, Changsha, China, 2015.

[6] H. Fang, Study on Fire Risk Assessment of Urban Electric Power Cable Tunnel, University of Science and Technology of China, Hebei, China, 2019.

[7] H. Zhang, L. V. Zonghui, L. I. Ang, and Z. H. O. U. Mei, "Statistical analysis of serious fires in China based on factor Analysis," Journal of the Armed Police Academy, vol. 35, no. 2, pp. 53-57, 2019.

[8] D.-E. Kim, N.-H. Kim, S.-H. Lim, and K. Gyung-Suk, "Condition monitoring technique for heating cables by detecting discharge signal," Journal of the Korean Institute of Electrical and Electronic Material Engineers, vol. 34, no. 2, pp. 136-141, 2021.

[9] S.-C. Yang, H.-Y. Kim, and O.-S. Kweon, "Experimental study of flame spread characteristics of a electric cable tray," Journal of The Korean Society of Hazard Mitigation, vol. 16, no. 4, pp. 31-35, 2016.

[10] T. Wang, X. Zhou, B. A. I. Gang, L. I. Chengyu, and Y. A. N. G. Xiaobin, "Hazard prediction of gas explosion induced by coal mine fire," Journal of China Coal Society, vol. 45, no. 12, pp. 4104-4110, 2020.

[11] W. Huang, C. Zhou, and X. Q. Wang, "Fire statistic and prevention measures for cables in power plant," Advanced Materials Research, vol. 614-615, pp. 1949-1952, 2013.

[12] X. Wang, L. I. A. O. Guangxuan, X. U. Tianrui, and C. A. I. Xin, "Real scale tests on cable tray fires to simulate actual end user's condition,"vol. 6, pp. 765-769, in Proceedings of the 5th International Symposium on Safety Science and Technology, vol. 6, pp. 765-769, SCIENCE PRESS USA INC, Changsha, China, August 2006.

[13] Z. Pascal, R. Hanouzet, and T. Beji, "Improved assessment of fire spread over horizontal cable trays supported by video fire analysis," Fire Technology, vol. 55, no. 1, pp. 233-255, 2019.

[14] J. Zheng, S. Liu, P. U. Lu, X. Su, X. Zhao, and X. U. Yang, "State of the art of combustion behavior of live power cables," Smart Power, vol. 48, no. 10, pp. 105-112, 2020.

[15] P. Huang, Q. I. N. Liang, Y. U. Longxing, S. Chen, L. I. N. Yuyao, and L. Huang, "Temperature field distribution of cable tray fire in utility tunnel," Journal of Fuzhou University (Natural Science Edition), vol. 49, no. 4, pp. 544-550, 2021.

[16] H. Zhang and Y. Zhao, "Study on underground utility tunnel fire characteristics under sealing and ventilation conditions," Advances in Civil Engineering, vol. 2020, Article ID 9128704, 11 pages, 2020.

[17] V. Babrauskas, "How do electrical wiring faults lead to structure ignitions?" in Proceedings of the Fire and Materials Conference 2001, pp. 39-51, London, UK, September 2001.

[18] J. J. Shea, "Identifying causes for certain types of electrically initiated fires in residential circuits," Fire and Materials, vol. 35, no. 1, pp. 19-42, 2011.

[19] V. Babrauskas, "Mechanisms and modes for ignition of lowvoltage, PVC-insulated electrotechnical products," Fire and Materials, vol. 30, no. 2, pp. 151-174, 2006.

[20] X. Gao, J. I. A. N. G. Yun, L. U. O. Junhua, and C. Yuan, "The principle of earlier period damage of XLPE power cable dueto temperature rise by overload," High Voltage Engineering, vol. 23, no. 2, pp. 62-64, 1997.

[21] D. U. Lin, Y. U. Huizong, and Y. A. N. Han, “A non-invasive temperature measurement method for high-voltage cable core based on temperature field construction and analysis," Transactions of China Electrotechnical Society, vol. 36, no. 7, pp. 1338-1346, 2021.

[22] R. S. Singh, J. Cobben, and V. Ćuk, "PMU-based cable temperature monitoring and thermal assessment for dynamic line rating," IEEE Transactions on Power Delivery, vol. 36, no. 3, pp. 1859-1868, 2021.

[23] D. Miyagi, N. Takata, and N. Takahashi, "Thermal analysis of co-axial multi-layered BSCCO HTS power cable," IEEE Transactions on Applied Superconductivity, vol. 21, no. 3, pp. 991-995, 2011.

[24] T. X. Sun, X. F. Zeng, Y. X. Lu, and H. J. Li, "Research on energy harvesting and its application in thermal condition monitoring of three-core power cables," in Proceedings of the 21st International Symposium on High Voltage Engineering (ISH), Budapest, Hungary, 28 November 2019.

[25] Y. H. Li, S. C. Ding, G. Liu, and C. Lei, "Study on relationship between thermal conductivity and core temperature of power cable," in Proceedings of the Asia-Pacific Power and Energy Engineering Conference (APPEEC), March 2011.

[26] T. A. O. Wenquan, Numerical Heat Transfer, Xi'an Jiaotong University Press, Xi'an, China, 2001.

[27] M. Lei, G. Liu, Y. Lai, J.-z. Li, W. Li, and Y. Liu, "Study on thermal model of dynamic temperature calculation of singlecore cable based on laplace calculation method," in Proceedings of the International Symposium On Electrical Insulation (ISEI), June 2010.

[28] Q. Hu, G. Liu, X. Ye, and L. Yan, "Three core cable hot field distribution and coaxial heat road model feasibility study," in Proceedings of the General Meeting of the IEEE-Power-andEnergy-Society (PES), July 2013.

[29] Y. Wang and X. Zhang, "Research on spontaneous cable fire early warning based on thermal circuit model with distribution parameters," Dynamic Systems and Applications, vol. 29, no. 8, pp. 2557-2570, 2020.

[30] M. E. N. G. Xiao-Kai, Z.-Q. Wang, and L. I. Guo-Feng, "Dynamic analysis of core temperature of low-voltage power cable based on thermal conductivity," Canadian Journal of Electrical and Computer Engineering, vol. 39, no. 1, pp. 59-65, 2016.

[31] M. Rerak and P. Ocłoń, "Thermal analysis of underground power cable system," Journal of Thermal Science, vol. 26, no. 5, pp. 465-471, 2017. 
[32] L. I. Bo, X. Zhang, and B. O. Chunbo, "Experimental study on early characteristics of internal cause of fire in power cable," Fire Science and Technology, vol. 38, no. 12, pp. 1772-1776, 2019. 